\title{
UMA ESCUTA DISCURSIVA DOS GRITOS: DECISÓES DE SCHRÖRINGER NUM APARELHO DE ESTADO $^{1}$
}

\section{A DISCURSIVE HEARING OF THE CRIES: SCHRÖDINGER DECISIONS IN AN STATE APPARATUS}

\author{
Phellipe Marcel da Silva Esteves \\ Universidade Federal Fluminense, UFF, Rio de Janeiro, RJ, Brasil
}

\begin{abstract}
Resumo: Neste artigo, pretendemos abordar alguns fenômenos discursivos em torno dos gritos dentro, em volta e relacionados às universidades. Para tal, mobilizamos a Análise do Discurso (sobretudo Pêcheux), com categorias como discursos cínico, autoritário, poder. Além disso, retomamos, de Althusser, a noção de Aparelho Ideológico de Estado, bem como a alegoria que Pêcheux acaba chamando de "efeito Münchhausen". Com isso, chegamos a uma proposta de pensar com outra alegoria, a de decisão de Schrödinger.
\end{abstract}

Palavras-chave: Universidade; Escola; AIEs; Movimento estudantil; Gritos.

Abstratc: In this article, our goal is to approach some discursive phenomena related to the crying in, around and associated to university. In order to do so, Pêcheux's Discourse Analysis is mobilized, and the main categories summoned here are cynical and authoritary discourses, as well as power. Besides, from Althusser, we convoke the notion of Ideological state apparatuses, and from Pêcheux, the so called "Münchhausen effect" allegory. With that, we come to a proposal of thinking another allegory: the Schrödinger decision.

Keywords: University; School; ISA; Student activism; Crying.

[...] Ano passado eu morri mas esse ano eu não morro

(BELCHIOR, "Sujeito de sorte", 1976).

\footnotetext{
${ }^{1}$ Este texto recapitula bastante do que apresentei na palestra de abertura da XX Semana de Iniciação Científica e III Encontro de Pós-Graduação da URCA (Universidade Regional do Cariri, Ceará) em 23 de outubro de 2017. O início de minha fala foi marcado por um protesto de alunos que tentavam negociar com a reitoria mais bolsas na universidade. (Não) coincidentemente, meu foco de apresentação eram protestos (de alunos, sindicatos de técnicos, associações docentes etc.).
} 
[...] aqui está o que é a máquina, uma camioneta que mata e engole os vestígios, que invenção útil e, além do mais, vista de fora, tem uns números escritos: quase parece ao longe um quadro de ardósia de uma escola ambulante que está a ensinar matemática aos meninos, e quem sabe talvez seja isso: vai matando e ensinando à medida que avança e por isso atrás de si ou fica nada, pois os mortos são atirados para dentro dessa baleia mecânica, ou ficam meninos alfabetizados, ou alfabetizados na matemática, aqui aprende-se o abc da matemática, o abc da linguagem não interessa, que faças cálculos mas que não consigas gritar (TAVARES, 2016, p. 50).

\section{Um lapso de escuta: gritos ignorados}

A metáfora das escolas como máquinas na história das ideias, sobretudo nas ideias em circulação nas artes e nos discursos estéticos, não é novidade. $\mathrm{Na}$ arte popular contemporânea, o videoclipe da música "Another Brick in the Wall” (Pink Floyd, 1982) é um exemplo inescapável: um estudante delira durante uma aula pensando em crianças, seus colegas, entrando, sob os grunhidos exasperados de um professor, em um abatedouro e tornando-se carne moída. Tavares, na epígrafe acima, estabelece a metáfora entre escolas e uma "camioneta", uma "baleia mecânica" que "vai matando e ensinando" a fazer cálculos, mas a que náo interessa o "abc da linguagem", uma vez que ele poderia promover o aprendizado dos gritos: e quem consegue controlar, domesticar ou mesmo significá-los?

Os gritos incomodam. Polissêmicos, às vezes domáveis apenas com o extermínio - seja simbólico, seja corporal -, produzem ecos facilmente. Abafá-los deve ser o objetivo de um aparelho de Estado. Para Souza (2011, p. 103), por exemplo, gritos (e sussurros) atuam no limiar da linguagem, articulando-se a memórias. Em Modesto (2018), vê-se o grito funcionando como acusação, sentença de morte, sofrimento, resistência. Apenas o (agente do) Estado pode e deve gritar, então é necessário desaprender o grito. Além de atuar na reprodução das condiçóes materiais de existência, de dominância e de dominação, caberia aos aparelhos de Estado também ensinar a falar no tom e no volume apropriados de voz.

Acontece que os aparelhos falham, e estudantes gritam: do ensino básico ao ensino superior.

Quando organizei, com um técnico e com um estudante de graduação da UERJ, o Hoje acordei pra luta!: intelectuais pela universidade pública (ESTEVES, PAVAN, SIQUEIRA, 2017), convidei os analistas do discurso Mónica Zoppi-Fontana e Lauro Baldini para escreverem 
um artigo. Em dado momento, conversamos brevemente logo sobre essa contradição: trabalhamos em instituiçóes que se inscrevem num aparelho de Estado que reproduz a ideologia dum modo não marcadamente violento, colaborando para a manutenção do Estado capitalista e do próprio Capital. Atuamos profissionalmente para a educação. Mais especificamente, quando lecionamos em cursos de licenciatura, formamos professores para as escolas. E estamos lutando, de algum modo e em certa medida, pela sobrevivência desse espaço de reprodução, das instituiçóes de ensino superior às de ensino básico. Num longo trecho de Althusser (1980 [1970], p. 51) sobre a escola, o filósofo questiona o que se aprende nela, chegando a uma resposta: "aprende-se o "know-how'". As escolas, portanto, seriam instituiçóes voltadas ao treinamento, principalmente profissional, dos estudantes, para seu futuro no mundo do trabalho capitalista, com posiçóes de classe mais ou menos definida. Mas não para por aí:

[...] ao mesmo tempo, e junto com essas técnicas e conhecimentos, aprendem-se na escola as "regras" do bom comportamento, isto é, as conveniências que devem ser observadas por todo agente da divisão do trabalho conforme o posto que ele esteja "destinado" a ocupar; as regras de moral e de consciência cívica e profissional, o que na realidade são regras de respeito à divisão social-técnica do trabalho e, em definitivo, regras da ordem estabelecida pela dominação de classe. Aprende-se também a "falar bem o idioma", a "redigir bem", o que na verdade significa (para os futuros capitalistas e seus servidores) saber "dar ordens", isto é (soluçâo ideal), dirigirse adequadamente aos operários etc. Enunciando este fato numa linguagem mais científica, diremos que a reprodução da força de trabalho não exige somente uma reprodução de sua submissão às normas da ordem vigente, isto é, uma reprodução da submissão dos operários à ideologia dominante por parte dos operários e uma reproduçáo da capacidade dos agentes da exploração e repressão, de modo a que eles assegurem também "pela palavra" o predomínio da classe dominante. Em outras palavras, a escola (mas também outras instituiçóes do Estado, como a Igreja e outros aparelhos como o Exército) ensina o "know-how" mas sob formas que asseguram a submissáo à ideologia dominante ou o domínio de sua "prática" (ALTHUSSER, 1980 [1970], p. 51-52).

E a Escola, como aparelho, de décadas para cá, tem chegado cada vez mais à universidade. Dito de outra maneira, com atividades profissionais que demandam cada vez mais saberes ditos de nível superior - um knowhow dependente de uma cultura e uma ciência inacessíveis até o ensino médio - os sujeitos precisam se ver com a quase obrigatoriedade de adquirirem capacidades, habilidades e domínios nas universidades. Além 
disso, a formação social capitalista contemporânea relega ao indivíduo o dever de sempre se "atualizar", se "reciclar", estar "atento às novidades". A universidade, com seus cursos superiores (da graduação às modalidades de pós-graduação) e de extensão acaba por ocupar esse espaço de formação estendida que fica a cargo náo das empresas, mas do trabalhador e da máquina pública (haja vista a expansão das universidades públicas nos últimos anos e também o aumento do financiamento integral ou parcial de mensalidades em faculdades privadas $)^{2}$.

O que estamos afirmando é que o período de inculcação, nos termos de Althusser, da ideologia dominante estendeu-se se consideramos o Brasil de 2019 em relação à França de 1970, tendo alcançado classes sociais não antes atingidas via interiorização das universidades, universalização do acesso, programas de cotas, aumento de investimentos com programas do tipo REUNI, fortalecimento de agências de fomento à pesquisa e, talvez principalmente, parceria com as universidades privadas com o Programa Universidade para Todos, PROUNI, e com o Fundo de Financiamento Estudantil, o FIES.

Esse processo de expansão não se dá sem falhas: a universidade, pelo menos no Brasil, historicamente é imaginada como um grotão de reserva de intelectualidade, autonomia de pensamento, ousadia epistemológica, científica, cultural. Não é nenhuma novidade que projetos como o Escola sem Partido tenham ganhado espaço nos últimos anos para tornar a universidade mais afim ao que deve ser uma escola. A crítica histórica da filosofia materialista de que a Escola é um espaço de inculcação ideológica - discursivamente, no sentido de reproduzir as ideologias dominantes por procedimentos parafrásticos de discursos autoritários - volta-se contra o próprio materialismo, ao afirmar-se que a Escola, ao contrário, é um espaço de doutrinação que rompe com valores tradicionais e conservadores. Ainda voltando a Althusser:

\begin{abstract}
Os mecanismos que produzem esse resultado vital para o regime capitalista são naturalmente encobertos e dissimulados por uma ideologia da Escola universalmente aceita, que é uma das formas essenciais da ideologia burguesa dominante: uma ideologia que representa a Escola como neutra, desprovida de ideologia (uma vez que é leiga), aonde os professores, respeitosos da "consciência" e da "liberdade" das crianças que lhes são confiadas [...],
\end{abstract}

\footnotetext{
${ }^{2}$ Expansão e aumentos virtuosos, em termos de financiamento público, muito apesar das numerosas críticas que podem ser feitas ao modelo. Não é o objetivo deste artigo entrar nessa celeuma, até porque o modelo atual (que é de "contingenciamento", leia-se "corte", na área da Educação, da superior à básica) deve ser o foco da discussão.
} 
conduzem-nas à liberdade, à moralidade, à responsabilidade adulta pelo seu exemplo, conhecimentos, literatura e virtudes "libertárias" (ALTHUSSER, 1980 [1970], p. 73-74).

Em recente artigo sobre o Escola sem Partido, Daltoé e Ferreira (2018) resumem esse desencontro que parece coincidente:

a escola é, portanto, lugar de doutrinação ideológica para o ESP [Escola sem Partido] e inculcação para Althusser, mas ambos se encontram de modo diverso, pois o efeito produzido é que o ESP quer justamente voltar à escola criticada por Althusser: uma escola reprodutora das relaçóes de exploração no modo de produçáo capitalista.

A diferença é que, na França de 1970, imaginar uma Escola como neutra e desprovida de ideologia era imaginá-la laica, sem religião, respeitosa. No Brasil dos anos 2010, quase 2020, produz-se um imaginário de universidade livre calcada em outros princípios, em outros efeitos de sentido. Um deles é o da aceleração do desenvolvimento científico, ou, ao menos, a aceleração dos índices de produção da ciência. Outro deles é a abertura para diversos públicos e classes sociais, por meio da implementação de mecanismos que possibilitem a permanência de graduandos de classes populares na universidade ao longo do período de sua graduaçáo.

Um processo que não se dá sem falhas e que é prenhe de imaginários: a universalizaçâo do ensino superior parte de imagens de classes sociais, e produz outras imagens também, como se as universidades (principalmente as federais) no Brasil inteiro fornecessem as mesmas oportunidades. Um desses mecanismos é a oferta de alimentação a preço módico feita em restaurantes universitários, o que, na UERJ, universidade em que atuei até 2018, só ocorreu em 2011 - mesmo com cotas raciais e sociais implementadas a partir de 2003. A inauguração do chamado "Bandejão" da UERJ dá-se depois de oito anos de reivindicaçáo por parte principalmente de alunos oriundos do sistema de cotas e é marcada por uma forte manifestação estudantil que não conseguia diálogo nem com o então reitor da universidade, nem com o então governador do estado do Rio de Janeiro, hoje o presidiário Sérgio Cabral Filho, à época chanceler da universidade.

Diante da tumultuada inauguração, que foi fechada para estudantes, mas para a qual o já criminoso Sérgio Cabral Filho foi convidado, a reitoria da UERJ lança uma nota mudando a designação do evento: de cerimônia de inauguração para teste para o funcionamento. Tal mudança de designaçáo 
é analisada em artigo de Deusdará e Rocha (2013). Um contraexemplo do que se quer de uma universidade pública, gratuita e de qualidade, mas também uma reintitulação de evento que leva a reflexóes discursivas interessantes: na ausência do governador, na ausência do diálogo, mas com maciça presença de quem ocuparia o espaço - ainda que nas idas e vindas de contratos com empresas terceirizadoras de serviço e comida -, o evento não pode ser chamado de inauguração, porque há grito. E gritos na Escola, como temos mencionado desde o início deste artigo, não devem ser tolerados pelo Estado. Se há grito, é teste. Mas há uma falha nesse processo de reintitulaçáo: se não é possível uma cerimônia de inauguração, mas sim um teste, o complemento nominal que preenche lugar sintático de "teste" mostra uma regularidade de que os gritos podem, devem e vão ocorrer: um teste de funcionamento. $\mathrm{O}$ bandejão da UERJ funcionará, e só funcionará, à base do grito. Caso contrário, encerra suas atividades ${ }^{3}$.

\section{Um lapso temporal: Brasília, 2019}

Damos aqui um salto de 2017 para 2019, no sentido de escutarmos discursivamente mais gritos, e ainda de estudantes. Com a eleição, em outubro de 2018, do candidato à presidência pelo PSL, os ministérios foram reestruturados e tanto o já previsto toma-lá, dá-cá quanto a diminuição das verbas em diversas áreas efetuaram-se. Sob diversos pretextos - tanto de coibir a militância nas universidades quanto de reajustar as contas públicas como modo de pressionar o Parlamento e a opiniáo pública a aprovarem a reforma da previdência -, em maio de 2019, um dos ministros da Educaçáo biônicos do governo PSL anuncia, cortes, contingenciamentos nas universidades públicas -que se estendem para as instituições federais de ensino básico, técnico e tecnológico não militares: de $30 \%$, ou de $3,5 \%$, ou

\footnotetext{
${ }^{3}$ Depois de 2011, foram várias as ocasiōes em que o restaurante universitário de UERJ fechou suas portas, e sob diversas alegações. Em 2017, o movimento estudantil, em sua heterogeneidade, ocupou o lugar e preparou, com a ajuda de doaçóes, ele mesmo comida para centenas de discentes ao longo de semanas. Depois da trágica morte do estudante Bruno Alves, que fazia parte da ocupação, o bandejão passa a se chamar Restaurante Universitário Bruno Alves, graças à campanha iniciada também pelo movimento estudantil, com gritos em diversas instâncias. Bruno Alves era estudante do sexto período do curso de História na universidade, tinha 34 anos e, com o atraso da bolsa que garantia sua presença na universidade, náo podia pagar a cara passagem de $\mathrm{R} \$ 4,20$ do trem para voltar para casa. Durante a ocupaçáo do bandejão, ao tentar subir a plataforma da estação Maracanã sem pagar a passagem, passando pela ferrovia, é atropelado por um trem. Uma morte pela qual o Estado é responsável, como tantas outras. Um caso exemplar daquilo que Mbembe (2016; 2018 [2003]) chama de necropoder.
} 
de $3 \%$, ou de $3,4 \%$, ou de uma fração de $13,8 \%$, ou de 3 bombons em caixas de 25 bombons cada... Não cabe aqui a reconstituição das versóes, mas é proveitoso discursivamente notar como o efeito provocado por essa torrente de números incongruentes é o de perplexidade, confusão. Em condiçôes de produção em que há atualizaçóes frequentes do discurso do Executivo federal e em que, dessas atualizaçóes, poucas saem de circulação, há de fato uma tempestade de versóes que vão ganhando corpo, de modo tanto a ser fácil mentir, desmentir, propor, despropor, afirmar e negar qualquer versão. Um discurso cínico. Um jogo sujo.

Importa adicionar que, com os cortes, há diversas manifestaçóes Brasil afora, em muitas instâncias. Gritos. Em audiência pública realizada em 22 de maio de 2019 a pedido das comissóes de Educação e Trabalho, e Administração e Serviço Público da Câmara dos Deputados, representantes da União Nacional dos Estudantes e da União Brasileira dos Estudantes Secundaristas (seus presidentes, respectivamente Marianna Dias e Pedro Gorki) pedem direito de fala para um diálogo com o ministro Abraham Weintraub. Os ânimos exaltam-se porque o ministro náo quer conversa com as entidades. A deputada Professora Marcilvânia, que conduzia os trabalhos na mesa, negocia com o ministro. $\mathrm{O}$ diálogo segue da seguinte maneira:

Sequência discursiva 1:

Deputada Professora Marcilvânia: "Ministro, o senhor quer ouvir a UNE?"

Ministro Abraham Weintraub: "Eu não quero falar com a UNE. Eles não são eleitos."

Deputada Professora Marcilvânia: "Você não quer falar com a UNE?"

Ministro Abraham Weintraub: "Eu nunca fui filiado à UNE."

Deputada Professora Marcilvânia: "Não, mas você quer ouvir a UNE?"

Ministro Abraham Weintraub: "A UNE? Não."

Deputada Professora Marcilvânia: "Nem a UBEs?"

Ministro Abraham Weintraub: "Nem a Ubes"

O Ministro da Educação, que não fala com os presidentes das principais entidades representativas de estudantes de ensino secundário e superior do Brasil numa audiência pública, discute cortes no ensino secundário e superior. Um discurso autoritário que, além de obrigar a falar de certa forma

\footnotetext{
${ }^{4}$ Ver mais em: <https://www.redebrasilatual.com.br/educacao/2019/05/ministro-de-bolsonaro-weintraub-recusa-dialogo-com-estudantes/>. Acesso em: 2 jun. 2019.
} 
- o grito não é tolerado, de modo que a polícia legislativa tenta retirar os presidentes das associaçóes, estudantes, da plenária -, não quer ouvir de nenhum modo o corpo discente. Até agora, tudo muito coerente: cinismo, autoritarismo e um discurso de ouvidos moucos. $\mathrm{O}$ autoritarismo não se resume a obrigar a náo dizer e a dizer de certa maneira (como já vimos com Orlandi, 1996), mas também a não ouvir aquilo que é dito, ignorar, negar-se ao diálogo. E também produzir discurso que reproduz que aluno não deve ocupar o mesmo lugar de professor. Como eu mesmo já ouvi de uma diretora de unidade acadêmica na universidade: "isso parece que foi escrito por um aluno". $\mathrm{Na}$ ocasião, escrevi um projeto de extensão, de fato, em coautoria com alunos da instituição. Curiosamente, eu mesmo havia escrito o trecho apontado pela diretora: um elogio ao esforço de diferentes gestôes do diretório acadêmico em elaborarem políticas duradouras, que fossem além das desavenças dos membros das chapas rivais. Encaro até hoje o autoritarismo como elogio. Acontece que ele se reproduz e vira fascismo. A Análise do Discurso é muito eficiente ao explicar: um indivíduo que se autoproclama progressista, democrático, de esquerda etc. pode reproduzir as práticas daninhas da ideologia dominante. E, nesse sentido, esbarramos em Foucault:

[...] para que o processo revolucionário não seja interrompido, uma das primeiras coisas a compreender é que o poder não está localizado no aparelho de Estado e que nada mudará na sociedade se os mecanismos de poder que funcionam fora, abaixo, ao lado dos aparelhos de Estado a um nível muito mais elementar, quotidiano, não forem modificados (FOUCAULT, 1979, p. 85).

Não se trata de negar os aparelhos de Estado - que tanto já mencionamos mais acima -, mas de situá-los em relação dialética com o funcionamento da ideologia para além deles. Mas, se estar nos aparelhos se afirmando progressista não garante sê-lo, isso traz uma notícia boa: há outros contraexemplos, ou ao menos paradigmas de prática universitária contra as quais nos colocamos. Não há reflexo entre a inserção nos aparelhos e a injunção à filiação a discursos de reprodução das condiçôes materiais de existência do Estado. Há buracos na paráfrase, no biopoder, no necropoder, na não escuta dos gritos e na desvalorizaçáo dos discentes em nome da repetição das instituiçôes tais quais são.

\section{Um lapso no aparelho}


Há lapsos nas universidades. E não no sentido de erros administrativos ou de garantia de direitos, mas sim no sentido de falhas no ritual. Para Zoppi-Fontana, as políticas científicas atuais são marcadas enunciativamente por espaços em que se materializam "temporalidades lançadas para o futuro em ritmo crescente de aceleraçáo", algo que afeta a subjetivação do cientista (ZOPPI-FONTANA, 2012, p. 234), mas que, em nossa visada, também promovem a contraidentificaçáo em relaçáo ao discurso de produção científica sob demanda, acelerada, prêt-à-porter. Segundo a autora,

[...] o mal-estar institucional em relação a certas novas práticas de autoria científica sinaliza a emergência deste sujeito cínico no espaço da produção acadêmica. Neste sentido, para nossa análise, a recente aparição quase simultânea de códigos de "boas práticas científicas", publicados pelas principais agências de fomento do país (por exemplo, CNPq e Fapesp), constitui um sintoma dos funcionamentos subjetivos que estudamos (ZOPPI-FONTANA, 2012, p. 248-249).

Os manuais de boas práticas científicas, bem como os contra plágio, funcionam de modo a corrigir um desvio em relação ao discurso científico dominante (e normativo). Funcionam, poderíamos afirmar, de modo a garantir que o aparelho de Estado seja bem-sucedido. $\mathrm{O}$ sujeito cínico na ciência é um modo de contraidentificar-se às demandas de produção científica. Zoppi-Fontana (2012) acrescenta a necessidade de pensar um espaço crítico de reflexão sobre a temporalidade da produção científica e a constituição do sujeito pesquisador-cientista, submetido a determinadas práticas e regras. Não se trataria, para a autora, propriamente de um retorno ao modelo positivista e "lento" de ciência preconizado, por exemplo, pelo movimento Slow Science. Seria, mais precisamente, a produção de outro modelo científico que não permitisse que encontrássemos "muito em breve nossa foto pendurada na entrada de nossos laboratórios, emoldurada pelo sorriso do palhaço feliz. Finalmente, cientista do mês" (ZOPPI-FONTANA, 2012, p. 250-251).

Entretanto, o ano de publicação do artigo de Zoppi-Fontana é 2012. Em 2019, o cenário e as condiçôes de produçấo para a pesquisa, o trabalho universitário, o tráfego pelas universidades é outro, e o horizonte não são alvissareiros. A universidade, como parte de um aparelho, é atacada fortemente, de modo que a falácia da crise tem conseguido adentrar inclusive o discurso da própria universidade, que passa a emanar a solução dos cortes e da captaçấo de recursos financeiros. Não apenas gestores externos 
(secretários e ministros da Educação) defendem essas saídas. O discurso é recorrente entre colegas pelos corredores. Voltando a Pêcheux,

[...] o poder está pronto a tudo, incluindo manipular a massa dos universitários e dos pesquisadores através do espectro da "crise", da "austeridade" e do "crescimento-zero"; ele organiza a escassez para suscitar a inquietude e docilidade das pessoas e desenvolver a concorrência entre as formaçôes de modo que sobrevivam e desenvolvam-se mais aptas a... servir o capitalismo na sua fase atual (PÊCHEUX, 2011 [1976], p. 236).

Este tempo cruel pode ser interpretado como uma oportunidade de transformar a própria universidade. É necessário repensar-se. E talvez disputar sentidos para o que pode ser universidade. Buscamos uma compreensão nesse (e uma disputa desse) sentido em Deusdará \& Esteves (2018), no tocante ao que tem significado, mas também a como pode significar a fórmula "autonomia universitária": a depender de como em que discurso ela se inscreve, pode dar mais margem às universidades de romper com sua circunscrição num aparelho de Estado. Já Baldini e Zoppi-Fontana (2017) afirmam:

Quando dizemos defesa da universidade tentamos justamente expor essas falácias na medida em que defender a universidade pública e o financiamento público da pesquisa é garantir um espaço coletivo de sobrevivência e alargamento de modos democráticos de coexistência, possibilitando o acesso ao trabalho intelectual a amplas parcelas da população. Educação é direito, acesso à universidade é direito, liberdade de pensamento e expressão é direito. $\mathrm{O}$ ataque à universidade pública é um ataque aos direitos fundamentais dos cidadãos e cidadãs do Brasil. Face ao despudor de quem nos governa, lutar pelos direitos garantidos na Constituição é um dever (BALDINI; ZOPPIFONTANA, 2017, p. 21).

Mas o que é necessário para salvaguardar a universidade e garantir sua continuidade, por um lado, e sua transformação, por outro? Como estabelecer uma frente de defesa aos direitos fundamentais dos cidadãos, alguns deles presentes na universidade? Consideramos que um dos primeiros passos é assegurar-se de que o sujeito que nela circula reconheçase como trabalhador: tanto a posiçáo de docente quanto a de estudante, e o reconhecimento e significaçáo do estudante como trabalhador por parte do docente. A angústia e a dor discente em muito se devem, em nossa interpretaçáo, à falta de reconhecimento de que o que fazem é um trabalho extremamente malremunerado (e isso quando remunerado), sem 
contribuição previdenciária (mesmo quando remunerado), em condiçôes insalubres (basta entrar em banheiros de qualquer universidade para concluir isso), sem sustento corporal (não são todas as universidades que dispôem de alimentação em preço acessível aos estudantes) ou condiçôes de acesso.

Entre colegas professores universitários, há algum elitismo na forma como lidamos com nossas atividades profissionais. Menciono aqui, de lembrança, alguns enunciados que me marcaram em diversos momentos reivindicatórios, sobretudo em greves:

Sequência discursiva 2:

a) Não somos metalúrgicos, somos professores universitários.

b) Podemos fazer melhor do que isso.

c) Precisamos construir formas alternativas de mobilização.

d) Greve é um modelo antigo, nós somos a vanguarda do pensamento, podemos fazer algo novo.

Note-se que todos esses enunciados são agrupados por certo elitismo intelectual. Às vezes falta algo à escuta, à interpretação de alguns trabalhadores do ensino superior. Em termos discursivos, diria que talvez a posição que ocupam discursivamente não lhes permite interpretar greves, movimentos paredistas, as ruas como um instrumento de luta. Ficam à busca de outras armas, e até encontram, principalmente do lado da estética ou da financeirização de suas atividades. Mas continuam sendo trabalhadores. Leiamos o que Lazzarato diz-nos:

Longe da fábrica, a nova composição de classe que emergiu ao longo desses anos é constituída por uma multiplicidade de situaçooses de emprego, de não emprego, de emprego temporário e de pobreza mais ou menos intensa. Ela está dispersa, fragmentada, precarizada, e está longe de adquirir os meios para ser uma "classe" política, ainda que constitua a maior parte da populaçáo (LAZZARATO, 2016, p. 12).

O problema, então, não é fazer greve ou não. É o de menos. É domesticar suas vozes e parar de gritar. Não se identificar como classe, como categoria de trabalhador numa conjuntura que exige que pensemos como classe e atuemos em coletividade, independentemente das filiaçóes individuais. Trata-se de um mínimo legado e patrimônio, carente ainda de muita transformação, a ser preservado. 


\section{Um lapso no cinismo: entre Münchhausen e Schrödinger}

Pêcheux (2009 [1975]) propóe uma alegoria da ordem do fantástico em sua teorização sobre o processo de constituição do sujeito:

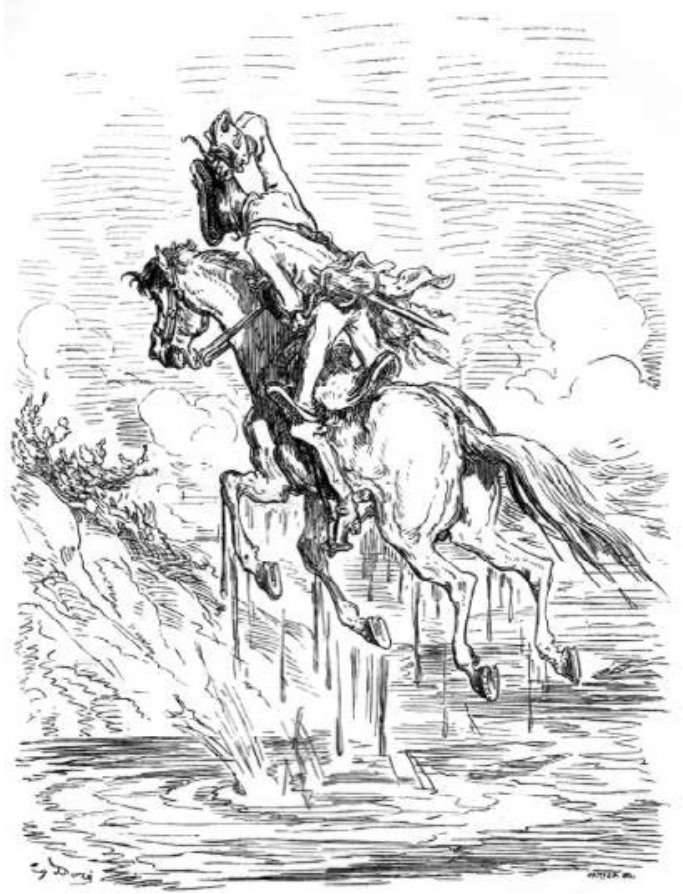

Figura 1: Barão de Münchhausen eleva a si e a seu cavalo de um pântano puxando-se pelos próprios cabelos. Ilustração de Gustave Doré na edição francesa de 1862.

$\mathrm{O}$ apagamento do fato de que o sujeito resulta de um processo, apagamento necessário no interior do sujeito como "causa de si", tem como consequência, a nosso ver, a série do que se poderia chamar as fantasias metafisicas, que tocam, todas, na questão da causa: por exemplo, a fantasia das duas mãos que, tendo cada uma um lápis, se desenham uma à outra sobre a mesma folha de papel e, também, a do salto perpétuo no qual, de um impulso prodigioso, se salta pro alto antes de se ter tocado o solo; poderíamos continuar. Vamos nos deter, propondo atribuir a esse efeito fantástico - pelo qual o indivíduo é interpelado em sujeito — o nome de "efeito Münchhausen", em memória do imortal barão que se elevava nos ares puxando-se pelos próprios cabelos (PÊCHEUX, 2009 [1975], p. 143-144). 
A cena foi traduzida para o discurso cinematográfico no filme Aventuras do barão de Münchhausen (GILLIAM, 1988). O Barão narra, na obra:

\begin{abstract}
Uma outra vez quis saltar um brejo mas, quando me encontrava a meio caminho, percebi que era maior do que imaginara antes. Puxei as rédeas no meio de meu salto, e retornei à margem que acabara de deixar, para tomar mais impulso. Outra vez me saí mal e afundei no brejo até o pescoço. Eu certamente teria perecido se, pela força de meu próprio braço, não tivesse puxado pelo meu próprio cabelo preso pelo rabicho, a mim e a meu cavalo segurava fortemente entre joelhos (GILLIAM, 1988, 1h18min30seg).
\end{abstract}

Pois bem, para Pêcheux, essa narrativa absurda em que o barão alemão safa-se da morte num gesto autocasual, numa autodeterminação, é uma boa figura para mostrar o efeito de autossurgimento, autoconsequência, autonomia do sujeito nas formaçôes sociais contemporâneas. E isso diz respeito a como os sujeitos constituem os discursos que produzem: creem ilusoriamente ser a origem do que dizem, creem poder controlar seus corpos, seus movimentos, suas articulaçôes.

Partimos dessa anedótica figura para outra. Trata-se do experimento mental - também fantástico - formulado por Erwin Schrödinger, em 1935, em resposta à interpretação de Copenhague da mecânica quântica. Schrödinger descreve um estado que poderíamos chamar de "vivomorto", baseado, alegoricamente, na impossibilidade de saber se um gato encaixotado morreu ou viveu a um possível envenenamento. De acordo com Schrödinger,

Qualquer um pode mesmo montar casos bem ridículos. Um gato é trancado dentro de uma câmara de aço, juntamente com o dispositivo seguinte (que devemos preservar da interferência directa do gato): num tubo contador Geiger há uma pequena porção de substância radioativa, táo pequena que talvez, no decurso de uma hora, um dos seus átomos decaia, mas também, com igual probabilidade, talvez nenhum se decaia; se isso acontecer, o tubo contador liberta uma descarga e através de um relé solta um martelo que estilhaça um pequeno frasco com ácido cianídrico. Se deixarmos todo este sistema isolado durante uma hora, então diremos que o gato ainda vive, se nenhum átomo decaiu durante esse tempo. A função- $\psi$ do sistema como um todo iria expressar isto contendo em si mesma o gato vivo e o gato morto simultaneamente ou dispostos em partes iguais (SCHRÖDINGER, 1935, p. 812$)^{5}$. ${ }^{5}$ Tradução disponível em diversas páginas da internet. O original diz o seguinte: "Man kann
auch ganz burleske Fälle konstruieren. Eine Katze wird in eine Stahlkammer gesperrt, zusam- 


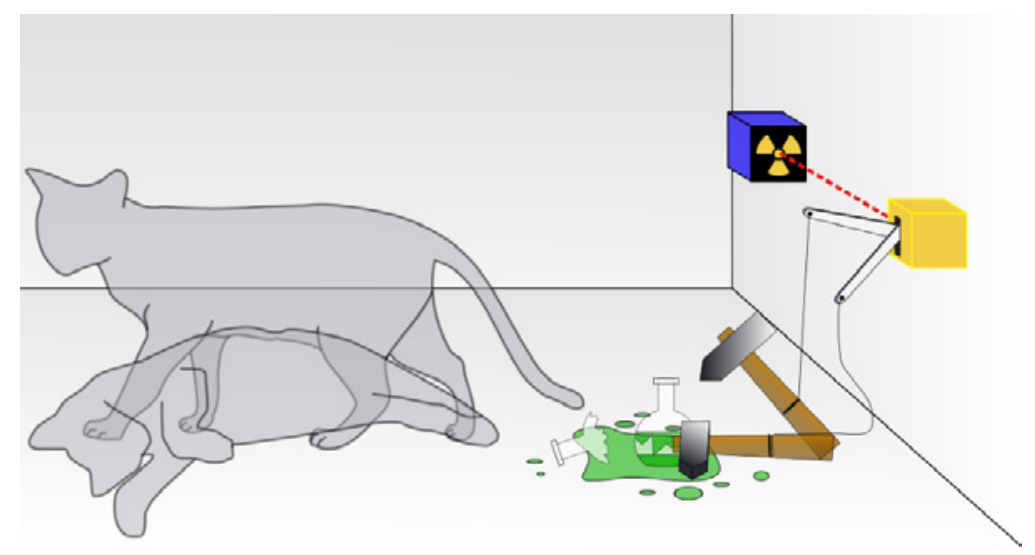

Figura 2: Ilustração do gato vivomorto de Schrödinger. Por Dhatfield, 2008.

Meu interesse aqui não é, em absoluto, falar de mecânica quântica, tampouco narrar como esse experimento, conhecido como "O gato de Schrödinger”, reverbera nas ciências exatas e tecnológicas. Seu valor, para mim, é justamente o de narrativa que pode ilustrar um funcionamento que tem a ver com muito mais do que com a física, a química, a matemática: atrela-se ao conhecimento, ao desconhecimento, à impossibilidade de previsão exata de funcionamentos náo necessariamente futuros, mas contemporâneos. E tem a ver mais propriamente com dois elementos das condiçôes de produção contemporâneas da universidade, como integrante do aparelho ideológico de Estado chamado Escola:

(1) a universidade como lugar de circulaçáo das ideias progressistas e da produçáo de ciência e tecnologia em prol de uma sociedade igualitária está viva e morta simultaneamente, vivamorta, uma vez que o veneno inoculado é e não é mortal: a universidade significa muitas coisas para além

men mit folgender Höllenmaschine (die man gegen den direkten Zugriff der Katze sichern $\mathrm{mu} \beta$ ): in einem GeIgerschen ZähIrohr befindet sich eine winzige Menge radioaktiver Substanz, so wenig, da $\beta$ im Lauf einer Stunde vielleicht eines yon den Atomen zerfällt, ebenso wahrscheinlich aber auch keines; geschieht es, so spricht das Zählrohr an und betätigt über ein Relais ein Hämmerchen, das ein Kölbchen mit Blausäure zertrümmert. Hat man dieses ganze System eine Stunde lang sich selbst überlassen, so wird man sich sagen, da $\beta$ die Katze noch lebt, wenn inzwischen kein Atom zerfallen ist. Der erste Atomzerfall würde sie vergiftet haben. Die $\psi$-Funktion des ganzen Systems würde das so zum Ausdruck bringen, da $\beta$ in ihr die lebende und die tote Katze (s. v. v.) zu gleichen Teilen gemischt oder verschmiert sind" (SCHRÖDINGER, 1933-1934, p. 812). 
da reprodução, mas está sendo atacada;

(2) qualquer decisão tomada por parte dos movimentos em defesa da universidade, seja como ela é, seja a universidade sonhada por diversas categorias, é certerrada, já que é impossível saber com qualquer nível de precisão se a estratégia adotada é certa ou errada, se ela vai culminar no fechamento da universidade, em sua salvação, em seu estrangulamento. É necessário levar em conta o processo. A única certeza que se tem, é que a insistência em fazer de tudo pensável e impensável, gritando, é a alternativa que pode fazer frente ao que se póe contra nós, ao inimigo que náo deixa de metamorfosear-se e que aparentemente não tem estratégia, uma vez que para destruir até mesmo a burrice ajuda, principalmente quando o que foi construído não foi alicerçado estruturalmente, não deu liga.

Se tomamos a noção pêcheuxtiana de formaçóes imaginárias para o movimento de reivindicação de manutenção/transformação das universidades, podemos afirmar que, ante à perversidade e ao cinismo, qualquer imagem formada sobre determinada decisão ser correta ou desacertada é extremamente instável. Qualquer mecanismo psíquico de antecipação resvala na impossibilidade de nem mesmo se vislumbrar uma imagem de saída, de solução, de estratégia. Uma das hipóteses que estabelecemos para essa luta inglória vivida nos últimos tempos é que isso que estamos chamando de universidade de Schrödinger e decisão de Schrödinger são consequências do funcionamento cínico e perverso do discurso e de outras práticas ideológicas do poder e também da própria universidade:

Dizer que o laço social se orienta, contemporaneamente, sob a forma da perversão e do cinismo não é sem consequências para uma análise discursiva que se queira materialista, pois estamos diante de uma nova maneira de os sujeitos se relacionarem com o que dizem, isto é, de estarem imersos numa prática discursiva que produz efeitos (BALDINI; DI NIZO, 2015, p. 145146).

Por um lado, temos uma universidade pautada no critério de alta produtividade, de captação de recursos financeiros privados, de formaçáo de recursos humanos. Por outro, um poder, uma política, em seus termos oficiais, cínica em seu tratamento à coisa pública. Cínica em relação às suas práticas da república. $\mathrm{O}$ que estamos dizendo é que, além de uma filiação de nossa grande política aos jogos e sistemas de evidência daquilo que podemos designar como ideologia de direita, de esvaziamento do Estado, 
temos sujeitos políticos que passam ao largo de uma identificação com o sujeito político, ou ao menos explicitam sem perfumaria a máxima de que a corrupção é inerente, constitutiva, da formação social capitalista. Ainda de acordo com Baldini e Di Nizo,

assim, além dos bons e maus sujeitos, e ainda dos que se desindentificam, teríamos a forma cínica de pertencimento de um sujeito à formação discursiva: um certo modo de relaçáo com o saber, em que o sujeito não se filia diretamente, nem se desfilia, mas permanece no horizonte de uma tomada de posição desengajada, ou de uma subjetivação assumida na forma de uma paródia (BALDINI; DI NIZO, 2015, p. 146).

Para voltar ao nosso caso, podemos dizer que há uma forma cínica de pertencimento à formaçáo discursiva política - que regula o que pode e deve ser dito no discurso político. O golpe consuma-se no cinismo das untuosas e perversas relaçóes entre Executivo, Legislativo e Judiciário, entre capitalismo nacional e imperialismo. Mas o que isso tudo tem a ver com a universidade? Bem, para resumir, o quadro que todas as universidades públicas brasileiras vivem hoje só é possível graças a discursos políticos dum lado cínicos e, doutro, perversos. E perverso no sentido de ultrapassar os limites de qualquer palavra, por mais violenta que seja. Ultrapassar todos os limites daquilo que é entendido como cruel, como engessamento, como destruição.

Com esse quadro, é valioso lembrar a frase do filósofo e historiador da arte Georges Didi-Huberman na mostra Levantes, que passou pelo SESCPinheiros (SP) em 2017, "Manifestar-se é um gesto. Pode ser um gesto de dança e pode ser um gesto de violência também, de revolta". A manifestação como dança, grito, riso, ciranda, corrida, tem sido necessária.

\section{Lapsos morrem e náo morrem}

Gostaria de fechar este artigo pontuando gestos de contra(ou des) identificação a discursos que defendem o fim da universidade ou um seu funcionamento exclusivo para as elites, completamente adequado a um aparelho ideológico de Estado. Não se trata de uma norma para a resistência, mas propriamente de análise de conjuntura:

a) Escutar os gritos dos alunos

b) Permitir-se gritar não autoritariamente 
c) Não ignorar a precarização

d) Reconhecer-se como trabalhador

Se o funcionamento da identificação cínica com o discurso pode ser resumida em um "sei que X está errado, mas ainda assim me inscrevo e insisto em X", há de se vislumbrar algo não exatamente simétrico, mas combativo ao discurso cínico. Sem que se caia no cinismo-perversão. Talvez um "sei que Y não dará certo, mas ainda assim me inscrevo e insisto em Y”. Pêcheux (1982 [1990]), em seu célebre "Delimitaçóes, inversóes, deslocamentos", cita uma passagem belíssima de um linguista muito conhecido entre nós, Émile Benveniste:

O homem sentiu sempre - e os poetas frequentemente cantaram - o poder fundador da linguagem, que instaura uma realidade imaginária, anima as coisas inertes, faz ver o que ainda não é, traz de volta o que desapareceu (BENVENISTE apud PÊCHEUX, 1990 [1982], p. 7).

A linguagem, em seu (extra)ordinário de sentido, é um demiurgo, é um construtor de universos. Para bem, para o mal e para todos os tons. A poesia percebe e faz uso. É por isso que, quando a linguagem usada pelo poder, pelos homens públicos, pelo Estado, começa a provocar efeitos de instabilidade diante de instituições como a universidade, ela começa a desfazer-se mesmo. Sem que seja necessário demolir uma rampa de concreto, deixar a grama crescer até se perder o horizonte, elas começam a cair. É necessário repetir: o presente dura muito tempo, e por isso mesmo acabou. Mas acabar não é morrer. Acabar é um fim, mas a história prossegue. Se quisermos algum futuro, já que esse presente acabou, é necessário resistir.

\section{Referências}

ALTHUSSER, Louis. Aparelhos Ideológicos de Estado. Tradução Maria Laura Viveiros de Castro. In: ALTHUSSER, Louis. Posiçóes 2. Rio de Janeiro: Graal, 1980. p. 46-101.

BALDINI, Lauro; DI NIZO, Patricia Leal. O cinismo como prática ideológica. Estudos da Língua(gem), Vitória da Conquista, v. 13, n. 2, p. 131-158, dez. 2015. Disponível em: <http://www.estudosdalinguagem.org/ index.php/estudosdalinguagem/article/view/476/429>. Acesso em: 3 mar. 2016.

BELCHIOR. Alucinaçáo. Álbum de música. Polygram, 1976. 
DALTOÉ, Andréia da Silva; FERREIRA, Ceila Maria. Ideologia e filiaçóes de sentido no Escola sem Partido. Linguagem em (Dis)curso, Tubarão, v. 19, n. 1, p. 209-227, jan./abr. 2019.

DEUSDARÁ, Bruno; ESTEVES, Phellipe Marcel da Silva. A polissemia da fórmula "autonomia universitária". Cad. Letras UFF, Niterói, v. 29, n. 57, p. 73-96, jan./jul. 2018.

DEUSDARÁ, Bruno; ROCHA, Décio. A interface linguagem-mundo como produção simultânea: quando estudantes enfrentam a administração central em uma universidade pública. Gragoatá, Niterói, n. 34, p. 263280, jan./jul. 2013. Disponível em: <http://www.gragoata.uff.br/index. php/gragoata/article/view/63/19>. Acesso em: 3 mar. 2016.

ESTEVES, Phellipe Marcel da Silva; PAVAN, Iuri; SIQUEIRA, Mauro (orgs.). Hoje acordei pra luta!: intelectuais pela universidade pública. Rio de Janeiro: EDUERJ, 2017.

FOUCAULT, Michel. Microfísica do poder. Tradução Roberto Machado. Rio de Janeiro: Graal, 1979.

GILLIAM, Terry (Dir.). As aventuras do Barão de Münchhausen. 1988.

LAZZARATO, Maurizio. Glossário do homem endividado. Tradução Daniel P. P. da Costa. São Paulo: N-1 Ediçôes, 2016.

MBEMBE, Achille. Necropolítica: biopoder, soberania, estado de exceção, política da morte. Tradução Renata Santini. Ver. Téc.: Cezar Bartholomeu. Arte \& Ensaios, Rio de Janeiro, n. 32, p. 122-151, 2016 [2003]. Disponível em: <https://revistas.ufrj.br/index.php/ae/article/view/8993/7169>. Acesso em: 5 jun. 2019.

. Necropolítica: biopoder, soberania, estado de exceção, política da morte. Trad.: Renata Santini. São Paulo: N-1 ediçóes, 2018 [2003].

MODESTO, Rogério. Interpelação ideológica e tensão racial: efeitos de um grito. Littera Online, São Luís, n. 17, p. 134-145, 2018. Disponível em: <http://www.periodicoseletronicos.ufma.br/index.php/littera/article/ view/10378/5981>. Acesso em: 20 dez. 2018.

ORLANDI, Eni. A linguagem e seu funcionamento: as formas do discurso. 4. ed. Campinas: Pontes, 1996.

PÊCHEUX, Michel. Delimitaçôes, inversôes, deslocamentos. Tradução José Horta Nunes. Cadernos de Estudos Lingüísticos, Campinas, n. 19, p. 7-24, jul./dez. 1990 [1982].

Posição sindical e tomada de partido nas ciências humanas e sociais 
[1976]. Tradução Lauro Baldini. In: Análise de discurso: Textos escolhidos por Eni Puccinelli Orlandi. Campinas: Pontes, 2011. p. 231251.

Semântica e discurso: uma crítica à afirmação do óbvio. 4. ed. Tradução Eni Orlandi [et al.]. Campinas: Unicamp, 2009 [1975].

RASPE, Rudolf Erich. Aventuras do baráo de Münchhausen. 9. ed. Tradução Orígenes Lessa. Rio de Janeiro: Global, 2016 [1785].

SCHRÖDINGER, Erwin. Die gegenwärtige Situation in der Quantenmechanik. Die Naturwissenschaften, Berlim (Alemanha), n. 23, v. 48, p. $98-$ 129, 29 nov. 1935.

SOUZA, Pedro de. Gritos e sussurros: rasgos vocais em discurso. In: CASTELO-BRANCO, Luiza Katia Andrade; ROGRIGUES, Eduardo Alves; SANTOS, Gabriel Leopoldino (Orgs.). Análise de discurso no Brasil: pensando o impensado sempre. Uma homenagem a Eni Orlandi. Campinas: RG Editora, 2011. p. 87-106.

TAVARES, Gonçalo M. Animalescos. Porto Alegre: Dublinense, 2016.

ZOPPI-FONTANA, Mónica Graciela. Slow Science: a temporalidade da ciência em ritmo de "impacto". Leitura, Maceió, v. 2, n. 50, p. 223-257, 2012. Disponível em: <http://www.seer.ufal.br/index.php/revistaleitura/article/view/1156/791>. Acesso em: 3 mar. 2013. 